\title{
Management options to recover perennial ryegrass populations and productivity in run-out pastures
}

\author{
Wendy M. GRIFFITHS ${ }^{1, *}$, Mike B. DODD ${ }^{2}$, Barbara KUHN-SHERLOCK ${ }^{1}$ and David F. CHAPMAN ${ }^{3}$ \\ ${ }^{1}$ DairyNZ, Private Bag 3221, Hamilton 3240, New Zealand \\ ${ }^{2}$ AgResearch Ltd, Private Bag 11008, Palmerston North 4410, New Zealand \\ ${ }^{3}$ DairyNZ, PO Box 85066, Lincoln University, Lincoln 7647, New Zealand \\ *Corresponding author: wendy.griffiths@dairynz.co.nz
}

\begin{abstract}
In parts of the upper North Island, farmers frequently report perennial ryegrass (Lolium perenne L.) pastures failing within 3 or 4 years post-sowing. This appears to be related to interactions between several factors: climatic (drier, hotter summers), biotic (insect pest), soil (texture, water-holding capacity) and grazing management factors that vary spatially and temporally. The efficacy of three management interventions for recovering ryegrass populations and production in runout pasture was assessed in an experiment initiated in 2018/19 in central Waikato. Treatments were a long-spring rotation (LSR), a longer grazing deferral during late spring and summer (pasture deferral, PD) and under-sowing with perennial ryegrass (US), each applied to pastures of four ryegrass cultivars. In the year after the treatments were implemented, the yield of ryegrass in $\mathrm{PD}$ was $2.4 \mathrm{t} \mathrm{DM} /$ ha greater than for the control (7-year-old pasture), and ryegrass tiller populations initially doubled but later declined. Yields in US and LSR were intermediate but not significantly different from the control. Ground score changes responded more positively to PD compared with the other treatments. Relative to the baseline prior to initiation of the study, tiller populations increased for PD and US but declined for control and LSR. There were no interactions between management treatment and cultivar for any of the variables measured. Pasture deferral shows promise as an intervention for recovering failing ryegrass pastures through natural reseeding. However, the longevity of the benefits observed here has yet to be determined.
\end{abstract}

Keywords: grazing deferral, long-spring rotation, perennial ryegrass yield, persistence, under-sowing

\section{Introduction}

Management guidelines for balancing dry matter (DM) yield and nutritive value of pastures based on perennial ryegrass (Lolium perenne L.) are well documented (Lee et al. 2008; Macdonald et al. 2010). Although perennial ryegrass is known for its plasticity and ability to adapt to different climates and management, the potential lifetime productivity of ryegrass-based pastures is not being realised, in part, due to their failure to persist beyond 4 years post-sowing in some regions (Clark 2011; Parsons et al. 2011). This is not a new phenomenon and, while knowledge of the factors involved (e.g., drought stress and pest damage, Lee et al. 2017; Chapman et al. 2015) and of the plant traits that may confer improved persistence (e.g., Faville et al. 2020; O'Connor et al. 2020) has increased in the past decade, the problem has not been solved. More information is required to unravel cultivar trait differences and their interaction with biotic and abiotic factors. The paucity of long-term trials has constrained a more comprehensive understanding.

Pasture productivity loss through declining tiller populations is expected to be exacerbated with projected climate change patterns, specifically increased frequency and intensity of summer moisture deficits (droughts, Beukes et al. 2021), and pest and diseases outbreaks (Mansfield et al. 2021). Because of the over-arching dominance of inter-annual variation in climate on total pasture yield, it is difficult to isolate single factors of importance or quantify the role of management in halting the decline in tiller populations (Lee et al. 2017).

In the last decade, farmers experiencing ryegrass persistence problems have resorted to under-sowing, often with shorter term (i.e., annual, Italian or hybrid) ryegrasses, to prolong the life of pastures (Dodd et al. 2018). This minimises the cost of pasture renovation but is still considered a sub-optimal solution which does not maintain the productive benefits of modern perennial ryegrass cultivars.

Two alternative management approaches have been proposed:

A longer spring rotation, also described as 'late control' (L'Huillier \& Aislabie 1988; Matthew et al. 1989, 1991; Hernandez Garay et al. 1997a,b), is based on the concept of extending the grazing interval in spring by 3 or 4 weeks to allow plants to develop into the early stages of reproductive growth. This is followed by hard grazing to remove the growing points of elongating tillers, allowing redistribution of carbon assimilates to stimulate production of new tillers. The window of opportunity is narrow because flowering 
tillers compete strongly for carbohydrates with new tillers and can cause their death (Matthew et al. 1991). When successful, the practice can rejuvenate tiller populations, increasing pasture production, particularly in the summer and autumn following implementation. However, adoption in the dairy industry has been limited because the resultant high pasture covers at grazing leads to high grazing residuals during late spring and summer, and thus limits the ability of farmers to capture the increased pasture production (Bishop-Hurley et al. 1997).

The second option is to defer grazing for a much longer period from late spring to mid summer (L'Huillier \& Aislabie 1988). This practice has been used to shift surplus pasture from late spring into summer when feed deficits occur, and DM has greater value (Harris et al. 1999; Devantier et al. 2017; Tozer et al. 2020). However, if managed in synchrony with the phenology of the ryegrass plant, it also enables recruitment of new ryegrass seedlings from seed shed by plants that have completed their reproductive cycle (L'Huillier \& Aislabie 1988). For re-seeding to be successful, pastures should be removed from grazing before the peak of flowering and not grazed until seed is mature.

The primary objective of our experiment was to compare the efficacy of these two management interventions alongside autumn under-sowing, in restoring ryegrass populations and productivity within a 7-year-old run-out pasture. As this experiment incorporated four different perennial ryegrass cultivars, a second objective was to explore the interaction between heading date and the three management interventions.

\section{Materials and Methods}

This experiment was superimposed on an earlier experiment (Lee et al. 2017, 2018) that was sown on 29 March 2011, on a Matangi silt loam soil at DairyNZ Scott Farm, Waikato (-37.772, 175.378; $40 \mathrm{~m}$ a.s.1). Four perennial ryegrass cultivars: 'Grasslands Nui' with standard endophyte, henceforth 'Nui SE', 'Commando AR37', 'Alto AR37' and 'Halo AR37' were originally selected to represent the range of functional types in commercially available perennial ryegrass in 2010. Nui is a diploid cultivar with a mid-season heading date (day $0=22$ October) which was released commercially in 1976 (Armstrong 1977). The other three cultivars were released after 2000. Commando is a diploid with a similar heading date to Nui while Alto (also a diploid) has a heading date 14 days later than Nui. Halo is a tetraploid, heading 25 days later than Nui (Lee et al. 2012).

Ryegrass seed was direct drilled at five sowing rates (equivalent to $6,12,18,24$ or $30 \mathrm{~kg}$ seed/ha), and white clover (Trifolium repens cv. 'Grasslands Tribute') was over-sown (equivalent to $8 \mathrm{~kg}$ seed/ha) on the soil surface the following day. Each cultivar $\times$ sowing rate treatment was replicated four times in a randomised block design within a single paddock.

The absence of significant cultivar or sowing rate treatment effects on the gradual decline in ryegrass content of the pastures over the first 6 years of the original experiment allowed a new trial design to be overlaid without confounding effects. Main treatment plots (cultivar, $540 \mathrm{~m}^{2}$ ) were divided into four subplots $\left(135 \mathrm{~m}^{2}\right)$, each allocated randomly to one of the management treatments.

\section{Treatments and implementation schedule}

The experiment comprised all combinations of the four ryegrass cultivars and four management treatments (control, long-spring rotation (LSR), seasonal pasture deferral (PD) and under-sowing (US)), replicated four times. The original replicate blocks were retained. The treatments were implemented at different times of the year. The timing of closure from grazing for the LSR and PD treatments was aligned with heading date to capitalise on the flowering characteristics of cultivars; 1 October 2018 for the two mid-season cultivars and 31 October 2018 for the two late-season cultivars.

The LSR treatment was closed from grazing for $\sim 48$ days. Plots were re-opened for grazing by mowing the pre-grazing herbage to a height of $80-100 \mathrm{~mm}$ using a Jenquip harvester (Harvester Concept Ltd., New Zealand). Lactating cows were then introduced to consume the cut material. Pre-grazing herbage mass at this harvest was estimated by cutting one $5 \mathrm{~m} \times$ $1.5 \mathrm{~m}$ strip to $50 \mathrm{~mm}$ height from each sub-plot using a Haldrup F-55 forage harvester (Haldrup $\mathrm{GmbH}$, Ilshofen, Germany). The cut herbage was weighed and one $150 \mathrm{~g}$ sub-sample was oven-dried $\left(95^{\circ} \mathrm{C}\right.$ for $\left.48 \mathrm{~h}\right)$ to determine DM percent.

Pre-graze mowing in this treatment resulted in a stubble of elongated stem basal material that cows were reluctant to graze, and this did not breakdown until June 2019. Following the first estimate of yield at re-opening, the cut height on the Haldrup harvester was adjusted to align with the post-grazing height from the preceding grazing which was generally $70-80 \mathrm{~mm}$ across all LSR plots. This harvesting protocol allowed for the estimation of harvestable pasture accumulation between grazings, using the same herbage sampling protocol described above.

Sub-plots assigned to the PD treatment were reopened for grazing $\sim 110$ days after closure (mid-late January 2019 for Nui SE and Commando AR37, and late February 2019 for Alto AR37 and Halo AR37). Standing herbage was fed in situ to lactating cows between morning and afternoon milking, followed by 
dry cows for 2 days, with all plots topped to a height of approximately $80 \mathrm{~mm}$ to tidy up the residual.

While the LSR and PD treatments were closed for grazing, the US and control treatments were grazed by lactating cows at intervals corresponding to typical grazing rotation length (23-41 days) from 1 October to 5 March. There were five grazing events over this period, each of 6 or 7 hours between morning and afternoon milking. For the US treatment, seed of perennial ryegrass cultivar 'One50' with AR37 endophyte was direct drilled at a rate equivalent to $10 \mathrm{~kg}$ seed/ ha on 2 April 2019. The control treatment followed recommended grazing management guidelines for dairy pastures. Further details including endophyte infection frequency can be found in Lee et al. $(2017,2018)$.

\section{Management}

All plots were grazed by dairy cows when herbage mass reached between 2600 and $3300 \mathrm{~kg} \mathrm{DM} / \mathrm{ha}$ to a target post-grazing residual of $1500 \mathrm{~kg} \mathrm{DM} / \mathrm{ha}$. Maintenance fertiliser was applied annually in autumn, and additional fertiliser was applied after soil tests in late spring to correct any nutrient deficiencies. Nitrogen (N) fertiliser was applied as urea five times, totalling $136 \mathrm{~kg} \mathrm{~N} / \mathrm{ha}$ in 2018/19 and $75 \mathrm{~kg} \mathrm{~N} / \mathrm{ha}$ in 2019/20. The lower rate in $2019 / 20$ was due to the very dry summer conditions and limitations imposed by the variable timing of harvests across treatments resulting from the experimental design.

\section{Measurements}

\section{Dry matter yield}

Herbage mass was estimated on all plots before each grazing by cutting one $5 \mathrm{~m} \times 1.5 \mathrm{~m}$ strip with the Haldrup harvester to a height of $50 \mathrm{~mm}$, except for the LSR treatment where the cut height varied as previously described. The location of the cut area was alternated between two halves of each sub-plot. The cut herbage was processed following the method described in the preceding section.

Seasonal pasture DM yield for each sub-plot was calculated from the individual harvest data partitioned into the following periods as defined in the DairyNZ Forage Value Index for the upper North Island (Chapman et al. 2017): winter (1 May to 30 June); early spring (1 July to 31 August); late spring (1 September to 31 October); summer (1 November to 31 January); and autumn (1 February to 30 April). Total annual pasture DM yield was calculated by summing seasonal data for the period 1 May 2018 to 30 April 2019 (incorporating the treatment implementation phases) and 1 May 2019 to 30 April 2020 (when all the treatments were in place and gradually came back into the same grazing frequency sequence by late spring 2019).

\section{Botanical composition and nutritive value}

Representative samples of herbage from each sub-plot were collected in spring, summer and autumn of both DM yield measurement years. Botanical composition was estimated from one sample of 30-45 $\mathrm{g}$ fresh weight collected from the harvester yield cut. Samples were dissected into categories of perennial ryegrass leaf, perennial ryegrass stem, other grasses, weeds, clover and dead matter, which were then oven dried at $95^{\circ} \mathrm{C}$ for $48 \mathrm{~h}$. Seasonal and total perennial ryegrass DM yield were estimated using both the leaf and the stem fractions.

When management interventions were applied (October 2018 to April 2019), harvest dates varied among treatments, and for mid- and late-season cultivars within the LSR and PD treatments. Samples were collected routinely from the control treatment for comparison with the LSR and PD treatments. Consequently, the timing of sampling did not always align with seasons. Botanical composition for months and plots without sample collection were estimated using linear interpolation of months with sample collection. Monthly botanical composition estimates were then averaged within season and used for perennial ryegrass yield estimation.

A further $150 \mathrm{~g}$ sub-sample of fresh herbage from the harvester cut was collected in each season in both years and oven-dried at $60^{\circ} \mathrm{C}$ for $48 \mathrm{~h}$. Dried material was ground to pass a $1 \mathrm{~mm}$-diameter sieve and analysed for metabolisable energy (ME) content $(\mathrm{ME}=\mathrm{DOMD}$ $\times 0.16$, Massey University Nutrition Laboratory, Palmerston North, New Zealand) using near infrared reflectance spectroscopy (Corson et al. 1999). When values for ME exceeded $12.5 \mathrm{MJ} / \mathrm{kg} \mathrm{DM}$, a default value of 12.51 was used for the analysis because higher values were outside the confidence limits of the calibrations.

\section{Perennial ryegrass tiller density and ground score}

Tiller population density changes were estimated from the total number of ryegrass tillers counted in nine frames $(10 \mathrm{~cm} \times 20 \mathrm{~cm})$ per sub-plot at permanently marked sites along a fixed diagonal transect. Frame locations were selected to identify with three initial levels of tiller density within each sub-plot: low density (three frames), medium density (three frames) and high density (three frames) along each transect. These positions were determined, and initial tiller populations sampled in the autumn before the implementation of the LSR and PD management interventions in the spring, and the US treatment in the following autumn.

The tiller density frames were located within larger frames $(40 \mathrm{~cm} \times 50 \mathrm{~cm})$ also at permanent sites along the fixed transect. These frames were used for ground scores using the National Forage Variety Trial (NFVT) protocol to estimate ryegrass cover 2 weeks post- 
grazing. A category of 0.5 was added to the standard 1-9 whole-number scale to better estimate ground cover at the low end of the scale. Visual scoring was undertaken in autumn before the start of management interventions and in the subsequent two autumns.

\section{Climate}

Weather data for the period March 2018 to June 2020 were obtained from the National Institute of Water and Atmospheric Research virtual climate station network (VCSN: -37.925, 175.325). Annual rainfall was 1079 $\mathrm{mm}$ in 2018/19 and $821 \mathrm{~mm}$ in 2019/20, compared with the preceding 10-year average of $1172 \mathrm{~mm}$. Summer rainfall from December to February inclusive was 238 $\mathrm{mm}$ in $2018 / 19$ and $80 \mathrm{~mm}$ in $2019 / 20$ (the 10-year average for the site is $235 \mathrm{~mm}$ ).

\section{Statistical analysis}

All analyses were performed using SAS 9.4 (SAS Institute Inc. 2016). Total annual and perennial ryegrass yields, and nutritive value, were analysed separately for each season using analysis of variance (ANOVA). Fixed effects included in the model were cultivar within heading date (mid vs. late), heading date, and management intervention. For yields, the model also included interactions between cultivar and management intervention and between heading date and management intervention. The model for ME did not include any interactions as sampling was conducted at different times depending on management intervention and heading date of the cultivar, resulting in a data set with various missing data patterns. Tiller population densities and ground scores for each plot were averaged within the low, medium and high frame groupings. Plot was included as a random factor and the covariance pattern model was unstructured. For tiller density and ground score change, the model included the autumn 2018 baseline value as a covariate. ANOVA was followed by pairwise comparisons between cultivars and between management interventions using Tukey's honestly significant difference (HSD) for multiple comparison adjustment. Data were $\log _{10}$ transformed if required to achieve homogeneity of variance of the residuals. Results are presented as least-squares means, standard error of the difference and P-values. Significance is declared if $\mathrm{P}$-value is $\leq 0.05$.

\section{Results \\ Total dry matter yield}

During the implementation period from spring 2018 to autumn 2019, the total DM yield was similar for all treatments in late spring and summer (Table 1). In autumn 2019, the total DM yield was lower for the LSR treatment (Table 1).

Total pasture production in the response period (the year following implementation of the US treatment in autumn 2019, 1 May 2019 to 30 April 2020) was in the range 8-9 t DM/ha across all treatments (Table 1). There were few significant cultivar, heading date, cultivar $\times$ management or heading date $\times$ management effects therefore only data for the main effects of management are presented.

There were significant treatment effects on seasonal and total DM yields in the response period. The PD treatment yielded more than the control treatment by $245 \mathrm{~kg} \mathrm{DM} / \mathrm{ha}$ in winter, $510 \mathrm{~kg} \mathrm{DM} / \mathrm{ha}$ in early spring and $245 \mathrm{~kg} \mathrm{DM} / \mathrm{ha}$ in autumn (Table 1). The total DM yield was greater for the PD treatment ( $9245 \mathrm{~kg} \mathrm{DM} / \mathrm{ha}$ ) compared with the control treatment $(8320 \mathrm{~kg} \mathrm{DM} / \mathrm{ha})$ but was not significantly different from the LSR (8450 $\mathrm{kg} \mathrm{DM} / \mathrm{ha})$ and US ( $8585 \mathrm{~kg} \mathrm{DM} / \mathrm{ha})$ treatments. Yields were similar across all treatments during late spring and summer when the dry conditions constrained pasture growth.

\section{Perennial ryegrass DM yield}

In the treatment implementation period, there were differences between treatments in perennial ryegrass yield. The PD treatment yielded the lowest in summer, as the plots were subjected to fewer harvests, while the LSR and US treatments yielded the greatest DM, with the control treatment intermediate (Table 2). Relative to late spring and summer, ryegrass DM yields in autumn were low for all treatments. The ryegrass yield of the LSR treatment was lower than the PD and US treatments but not significantly different to the control. The control, PD and US treatments were not significantly different from each other (Table 2).

During the response period, pastures in the PD treatment had approximately $18 \%$ greater perennial ryegrass content (DM basis) and a $2.4 \mathrm{t} \mathrm{DM} /$ ha ryegrass DM yield advantage compared with the control treatment $(\mathrm{P}<0.001$, Table 2$)$. Total ryegrass yield in the PD treatment was also significantly greater than in the LSR and US treatments by approximately 1.8 and $1.4 \mathrm{t}$ $\mathrm{DM} / \mathrm{ha}$, respectively. The ryegrass DM yield advantage in the PD treatment was observed in all seasons except in summer (Table 1). Perennial ryegrass DM yield did not differ among the control, LSR and US treatments apart from in late spring when the US treatment outperformed the control treatment but was not significantly different to the LSR treatment. Pairwise comparison between the control and US treatment showed that the additional 1 t DM/ha annual yield advantage to the US treatment reached significance at the $10 \%$ level $(\mathrm{P}=0.051)$.

\section{Ryegrass tiller populations and ground score}

In autumn 2018, before the implementation of the treatments, ryegrass tiller population density averaged approximately 2500 tillers $/ \mathrm{m}^{2}$ across the experimental 
area, and there were no significant differences in tiller density or ground score between areas allocated subsequently to different management treatments (Table 3). In autumn 2019, ryegrass tiller populations in the PD treatment exceeded 6000 tillers $/ \mathrm{m}^{2}$. One year following treatment implementation, the tiller density in the PD treatment was significantly greater than in the control and LSR treatments $(\mathrm{P}<0.001)$ but not different to the US treatment.

Mean ground score increased between autumn 2018 and autumn 2020 in all treatments, and the effect of treatment was significant $(\mathrm{P}<0.001$, Table $3)$. The relative change in ground score over time in response to management treatment closely mirrored

Table 1 Effect of management intervention on total pasture yield ( $\mathrm{kg} \mathrm{DM} / \mathrm{ha}$ ) from 1 July 2018 to 30 April 2019 (treatment period) and from 1 May 2019 to 30 April 2020 (response period of 1 year following the implementation of treatments). SED = standard error of difference. Within a row, values followed by different letters are different at $\mathrm{P}<0.05$.

\begin{tabular}{|c|c|c|c|c|c|c|}
\hline & \multicolumn{4}{|c|}{ Management intervention } & \multirow[b]{2}{*}{ SED } & \multirow[b]{2}{*}{ P-value } \\
\hline & Control & Deferred & $\begin{array}{l}\text { Long-spring } \\
\text { rotation }\end{array}$ & Under-sowing & & \\
\hline \multicolumn{7}{|l|}{ Treatment period } \\
\hline Late spring 2018 & 3225 & 3030 & 3300 & 2900 & 253.3 & 0.379 \\
\hline Summer 2018/2019 & 5400 & 5255 & 5435 & 5460 & 294.7 & 0.902 \\
\hline Autumn 2019 & $1175 \mathrm{a}$ & $1435 \mathrm{a}$ & $300 \mathrm{~b}$ & $1425 \mathrm{a}$ & 164.6 & $<0.001$ \\
\hline \multicolumn{7}{|l|}{ Response period } \\
\hline Winter 2019 & $745 b$ & $1590 \mathrm{a}$ & $735 b$ & $890 \mathrm{~b}$ & 126.7 & $<0.001$ \\
\hline Early spring 2019 & $1385 b$ & $1895 \mathrm{a}$ & $1505 b$ & $1580 a b$ & 143.2 & 0.006 \\
\hline Late spring 2019 & 3045 & 2880 & 3070 & 3145 & 149.1 & 0.335 \\
\hline Summer 2019/2020 & 2870 & 2545 & 2840 & 2700 & 199.2 & 0.349 \\
\hline Autumn $2020^{1}$ & $275 b$ & $520 \mathrm{a}$ & $300 \mathrm{~b}$ & $265 b$ & 45.5 & $<0.001$ \\
\hline Total annual & $8320 \mathrm{~b}$ & $9245 \mathrm{a}$ & $8450 a b$ & $8585 a b$ & 398.6 & 0.034 \\
\hline
\end{tabular}

${ }^{1}$ one harvest collection missed due to covid-19 lockdown

Table 2 Effect of management intervention on perennial ryegrass yield (kg DM/ha) from 1 July 2018 to 30 April 2019 (treatment period) and from 1 May 2019 to 30 April 2020 (response period of 1 year following the implementation of treatments). SED $=$ standard error of difference. Within a row, values followed by different letters are different at $P<0.05$.

\begin{tabular}{|c|c|c|c|c|c|c|}
\hline & \multicolumn{4}{|c|}{ Management intervention } & \multirow[b]{2}{*}{ SED } & \multirow[b]{2}{*}{ P-value } \\
\hline & Control & Deferred & $\begin{array}{l}\text { Long-spring } \\
\text { rotation }\end{array}$ & Under-sowing & & \\
\hline \multicolumn{7}{|l|}{ Treatment period } \\
\hline Late spring 2018 & 1845 & 1350 & 1790 & 1550 & 195.8 & 0.053 \\
\hline Summer 2018/19 & $2050 \mathrm{~b}$ & $985 \mathrm{c}$ & 2955 a & $2290 \mathrm{~b}$ & 174.3 & $<0.001$ \\
\hline Autumn 2019 & $190 \mathrm{ab}$ & $265 a$ & $140 \mathrm{~b}$ & 285 a & 40.7 & 0.003 \\
\hline \multicolumn{7}{|l|}{ Response period } \\
\hline Winter 2019 & $335 b$ & $885 a$ & $420 \mathrm{~b}$ & $495 \mathrm{~b}$ & 91.5 & $<0.001$ \\
\hline Early spring 2019 & $700 \mathrm{~b}$ & $1405 a$ & $925 \mathrm{~b}$ & $1020 \mathrm{~b}$ & 127.4 & $<0.001$ \\
\hline Late spring 2019 & 1655 c & $2405 a$ & $1890 \mathrm{bc}$ & $2150 a b$ & 166.4 & 0.001 \\
\hline Summer 2019/2020 & 1165 & 1440 & 1250 & 1230 & 115.1 & 0.114 \\
\hline Autumn $2020^{1}$ & $130 \mathrm{~b}$ & $315 a$ & $155 b$ & $130 \mathrm{~b}$ & 33.0 & $<0.001$ \\
\hline Total annual 2019/20 & $3985 \mathrm{~b}$ & $6450 \mathrm{a}$ & $4640 \mathrm{~b}$ & $5025 \mathrm{~b}$ & 391.4 & $<0.001$ \\
\hline
\end{tabular}

${ }^{1}$ one harvest collection missed due to covid-19 lockdown 
relative changes in tiller density. The exception was the separation in scores for the PD and US treatments. This result was supported further by a sub-plot ground score assessment conducted in June 2020 (treatment effect significant at $\mathrm{P}<0.001$, data not shown).

\section{Nutritive value}

In winter and late spring 2018, ME did not differ among pasture areas allocated subsequently to the different management treatments (mean $12 \mathrm{MJ} / \mathrm{kg} \mathrm{DM}$, $\mathrm{P}>0.05$ ). Thereafter, the US treatment was considered synonymous with the control treatment until the US intervention was implemented in April 2019. During the implementation phase for the LSR and PD treatments, estimates of ME were paired with the closest available data for the control treatment within the same season.

The ME of pastures based on the mid-season heading cultivars in the LSR treatment at re-opening in midNovember was 1.4 units lower compared with the control treatment ( 9.8 vs. $11.2 \mathrm{MJ} / \mathrm{kg}$ DM, respectively; $\mathrm{P}<0.001)$. In late December when the LSR treatment was re-opened on the late-season heading cultivars, the difference between the LSR and control treatment was 1.1 units (9.7 vs. $10.8 \mathrm{MJ} / \mathrm{kg} \mathrm{DM}$, respectively; $\mathrm{P}<0.0001)$.

A similar pattern was evident in the PD treatment. The ME of the standing herbage for the mid-season cultivars at re-opening in mid-late January was $7.5 \mathrm{MJ} /$ $\mathrm{kg}$ DM; approximately 3 units lower than the control treatment $(10.7 \mathrm{MJ} / \mathrm{kg} \mathrm{DM}, \mathrm{P}<0.0001)$. At the time the late-season heading PD treatment was re-opened in late-February, ME of pasture in the control treatment had declined sharply and there was no significant difference between the control and PD (late-heading) treatments ( 7.7 vs. $7.3 \mathrm{MJ} / \mathrm{kg} \mathrm{DM}$, respectively). In the following year, the ME of pasture in the PD treatment was approximately 0.4 and 0.2 units greater in winter $(\mathrm{P}<0.01)$ and late spring $(\mathrm{P}<0.01)$, respectively, compared with the other management intervention treatments.

\section{Discussion}

The objective of this experiment was to compare three management interventions: LSR, PD and US with a control for recovering perennial ryegrass populations and productivity in 7-year-old run-out dairy pastures.

The PD treatment was effective in increasing ryegrass tiller density and ryegrass DM yield, relative to the control, in the year following treatment implementation. The increase in ryegrass yield was 1.6-times the yield of the control and was the result of rebuilding plant density and changing the sward structure, with the latter reflected better in the ground score data than the tiller density data.

There was a strong short-term response in the ryegrass tiller density in the PD treatment with the response more than doubling the initial population. Our observations indicate that this was mainly a function of the emergence of new seedlings. This effect was much greater than that achieved by US in 2019. However, we observed a halving of tiller numbers between autumn 2019 and autumn 2020. This was most likely a result of competition between young plants via size-density compensation (Matthew et al. 1995). A decline in tiller

Table 3 Management intervention effects on perennial ryegrass tiller density (tillers $/ \mathrm{m}^{2}$ ) and ground score (0.5-9) and change in tiller density and ground score (covariate adjusted) between autumn 2018 and autumn 2020. SED = standard error of difference. Within a row, values followed by different letters are different at $\mathrm{P}<0.05$.

\begin{tabular}{|c|c|c|c|c|c|c|}
\hline & \multicolumn{4}{|c|}{ Management intervention } & \multirow[b]{2}{*}{ SED } & \multirow[b]{2}{*}{ P-value } \\
\hline & Control & Deferred & $\begin{array}{l}\text { Long-spring } \\
\text { rotation }\end{array}$ & Under-sowing & & \\
\hline \multicolumn{7}{|l|}{ Ryegrass tiller density } \\
\hline Autumn 2018 (Apr) & 2390 & 2380 & 2610 & 2440 & 322.1 & 0.890 \\
\hline Autumn 2019 (May) & $2830 \mathrm{~b}$ & $6390 \mathrm{a}$ & $2700 \mathrm{~b}$ & $2790 \mathrm{~b}$ & 480.6 & $<0.001$ \\
\hline Autumn 2020 (Jun) & $1970 \mathrm{c}$ & 3140 a & $2240 \mathrm{bc}$ & $2760 a b$ & 219.8 & $<0.001$ \\
\hline \multicolumn{7}{|l|}{ Ground score } \\
\hline Autumn 2018 (Apr) & 2.2 & 2.2 & 2.0 & 2.1 & 0.29 & 0.906 \\
\hline Autumn 2020 (Jun) & $2.8 \mathrm{~b}$ & $4.9 \mathrm{a}$ & $3.2 \mathrm{~b}$ & $3.6 \mathrm{~b}$ & 0.33 & $<0.001$ \\
\hline \multicolumn{7}{|l|}{ Tiller density change } \\
\hline Autumn 2018 - Autumn 2020 & $-470 c$ & $700 \mathrm{a}$ & $-250 \mathrm{bc}$ & $310 a b$ & 215.4 & $<0.001$ \\
\hline \multicolumn{7}{|l|}{ Ground score change } \\
\hline Autumn 2018 - Autumn 2020 & $0.6 \mathrm{c}$ & $2.8 \mathrm{a}$ & $1.1 \mathrm{bc}$ & $1.5 b$ & 0.31 & $<0.001$ \\
\hline
\end{tabular}


population from the autumn peak following deferral to 12 months post-deferral was also noted by McCallum et al. (1991) and raises a concern about the longevity of the benefit. The data of Lee et al. $(2017,2018)$ also showed a significant decline in ryegrass tiller populations, which they attributed to successive summer droughts, and it is possible that the newly replenished population of tillers in the PD treatment was affected in the same way, given the extremely low summer rainfall in early 2020. Measurements on the current experiment are ongoing to assess the long-term benefit of grazing deferment in late spring and summer on DM yield and tiller density.

Initial tiller populations in this study averaged approximately 2500 tillers $/ \mathrm{m}^{2}$, which is sub-optimal for ryegrass pastures and indicative of poor productivity, compared with a renewed dairy pasture of 5000+ tillers $/ \mathrm{m}^{2}$ (L'Huillier \& Aislabie 1988; Bahmani et al. 1997; Lee et al. 2018). At this point on the tiller density trajectory, the benefit of pasture deferral was less obvious when considering total pasture DM yield, because of the strong presence of other species, particularly paspalum (Paspalum dilatatum) which compensated for the absence of ryegrass. Less desirable species can maintain overall yield well, as indicated by the late spring and summer yields for the control treatment in Table 1 vs. Table 2. The deferred pastures produced approximately $11 \%$ more total DM $(+926 \mathrm{~kg} \mathrm{DM} / \mathrm{ha})$ than the control in the year following deferral, and the response was in the range of $6-20 \%$ reported in other studies investigating pasture deferral (McCallum et al. 1991; Harris et al. 1999; Tozer et al. 2020). Rejuvenation of pastures through recruitment of new plants via pasture deferral was more successful than via the mode of increased tillering of existing plants in the LSR treatment. The perceived benefits of a laxer spring grazing management for increasing tiller populations and pasture productivity (L'Huillier \& Aislabie 1988; Matthew et al. 1991), were not realised in this study. Similar observations in a self-contained farmlet experiment were noted by Bishop-Hurley et al. (1997) and attributed to the challenges inherent with maintaining target residuals.

In the current study, the pre-grazing herbage was mown to a height of $80-100 \mathrm{~mm}$ at re-opening to ensure that the meristem was protected from herbivory and to encourage tillering at the peak of the annual cycle, a time when environmental conditions are generally favourable for plant growth and development. However, anecdotal observations in autumn following the 2019/20 drought were of a clumpy distribution of plants, with a high number of tillers and this was probably insufficient to achieve canopy closure. In a glasshouse study using ryegrass plants in plastic pots, Hernandez Garay et al. (1999) reported an 80- or 120-mm cutting height resulted in optimal herbage accumulation, with gains being captured through adjustment in tiller weight compared with tiller density. Furthermore, Hernandez Garay et al. (1997a,b) suggested that an extended spell of lax grazing of up to 12 weeks (mid-September to December closure) induced greater positive changes in tiller patterns compared with a closure of 6 weeks (late October to December). A longer closure may be more critical for initiating and prioritising root production for increased survival under summer environmental stresses, therefore, the balance between above- and below-ground production warrants investigation. It is conceivable that there is an optimum tiller density threshold for implementing a LSR treatment to capture the perceived benefits in summer-autumn pasture production, and pastures in the current study were below this threshold, such that further inferences cannot be made from the data presented.

The US treatment accumulated significantly more perennial ryegrass DM compared with the control in late spring and approximately $1 \mathrm{t} \mathrm{DM} / \mathrm{ha}$ greater for the year compared with the control. While the latter response did not reach significance, it is of biological relevance, and the result is supported by the change in tiller density and ground score between 2018 and 2020. Monitoring of this treatment for a further season will provide data on whether there is a lag in the growth of the new 'stitched-in' plants. Any lag effect may have been associated with the drought conditions that materialised in late spring and/or suppression from the lower rates of $\mathrm{N}$ applied, which was an artefact of the timing of grazing across treatments.

In this study, the timing of closure and re-opening to grazing in the PD treatment (early and late October closure for mid- and late-season heading cultivars, respectively) was aligned with heading date to capitalise on the timing of the plant's reproductive cycle for both functional groups. This 'staggered' strategy ensured that reproductive tillers had sufficient time to mature and shed seed, optimising the establishment of a new population of plants to increase productivity. Had these timeframes not been optimal, a smaller or nil treatment effect may have been observed and potentially an interaction between heading date and ryegrass DM yield.

The PD treatment was re-opened to grazing when there was visual evidence of significant seed-drop and in the current study this occurred for both functional groups earlier than the late February-early March recommended by McCallum et al. (1991). However, the re-opening date for the mid-season heading group in this study matched well with the mid-January date noted by L'Huillier \& Aislabie (1988). Recent studies documenting the variation in perennial ryegrass phenology and reproductive development curves (Wims et al. 2014; Griffiths et al. 2017) have provided 
the detailed knowledge for successful implementation of deferred grazing at the farm scale for a wide range of commercially available ryegrass cultivars.

Maintaining pasture quality in spring has been an area of key focus for farmers. Grazing pastures between the 2- and 3-leaf stage promotes rapid growth and accumulation (Fulkerson \& Donaghy 2001). Combining this with hard grazing during late spring where grazing removes the apical meristem and inhibits the growth of flowering tillers, ensures a supply of high-quality feed. However, with the current knowledge and future projections of increased frequency and intensity of biotic and abiotic environmental stresses, a continued reliance and focus on the DM trait carries a significant cost in terms of pasture resilience. A re-think of the optimal grazing management strategies to re-address the balance among the forage traits: DM yield, nutritive value, and persistence to improve pasture resilience, should be encouraged, acknowledging that environmental traits are also becoming increasingly important.

Pastures closed for 6-8 weeks hold their nutritive value well (Bishop-Hurley 1997), as supported by the ME in the current study for the LSR treatment. Extending beyond 6-8 weeks and out to approximately 4 months, the ME of deferred standing pasture declined significantly, as expected, and the estimated ME of approximately 7 or $8 \mathrm{MJ} / \mathrm{kg} \mathrm{DM}$ was similar with that reported by Tozer et al. (2020) for hill country sheep and beef farms. During a dry summer as experienced in the current study, there was little difference in ME between the deferred pasture and the control for the late-season heading group. The deferred pasture did, however, under the climatic conditions, provide a feed supply without incurring additional conservation costs associated with harvesting or feeding out. There was also evidence of a lag in pasture quality with resulting downstream benefits in nutritive value in the winter and spring following re-seeding.

\section{Conclusion}

The management practice of PD was successful in increasing tiller populations, ground score and DM yield of perennial ryegrass in the short-term. Indications of declining tiller populations suggest that this benefit may be short-lived. The LSR treatment did not rejuvenate failing perennial ryegrass pastures under the conditions imposed in this study, and it is plausible that this result reflects the severely run-out state of the swards. Undersowing boosted pasture production in the following spring, and increased tiller populations compared to the control treatment. The study will continue during the production season of 2020/21 to enable quantification of the on-going efficacy of intervention treatments aimed at reversing the losses in ryegrass performance due to persistence failure.

\section{ACKNOWLEDGEMENTS}

We thank the DairyNZ technical and farm staff teams for their valuable contributions to the field work. This research was funded by New Zealand dairy farmers through DairyNZ Inc. (RD1410).

\section{REFERENCES}

Armstrong CS. 1977.'Grasslands Nui perennial ryegrass (Lolium perenne L.). New Zealand Journal of Experimental Agriculture 5: 381-384. https://doi. org/10.1080/03015521.1977.10426000

Beukes PC, Babylon A, Griffiths WM, Woodward SJR, Kalaugher E, Sood A, Chapman DF. 2021. Modelling perennial ryegrass (Lolium perenne) persistence and productivity for the Upper North Island under current and future climate. In: Douglas GB. Ed. Resilient Pastures Symposium. Grassland Research and Practice Series 17. Dunedin, New Zealand: New Zealand Grassland Association, pp. 297-306. https:// doi.org/10.33584/rps.17.2021.3450

Bahmani I, Thom ER, Matthew C. 1997. Effects of nitrogen and irrigation on productivity of different ryegrass ecotypes when grazing by dairy cows. Proceedings of the New Zealand Grassland Association 59: 117-123. https://doi.org/10.33584/ jnzg.1997.59.2274

Bishop-Hurley GJ, Matthews PNP, Hodgson J, Dake C, Matthew C. 1997. Dairy systems study of the effects of contrasting spring grazing managements on pasture and animal production. Proceedings of the New Zealand Grassland Association 59: 209-214. https://doi.org/10.33584/jnzg.1997.59.2243

Chapman DF, Muir PD, Faville MJ. 2015. Persistence of dry matter yield among New Zealand perennial ryegrass (Lolium perenne L.) cultivars: insights from a long-term data set. Journal of New Zealand Grasslands 77: 177-184. https://doi.org/10.33584/ jnzg.2015.77.463

Chapman DF, Bryant JR, Olayemi ME, Edwards GR, Thorrold BS, McMillan WH, Kerr GA, Judson G, Cookson T, Moorhead A, Norris M. 2017. An economically-based evaluation index for perennial and short-term ryegrasses in New Zealand dairy farm systems. Grass and Forage Science 72: 1-21. https:// doi.org/10.1111/gfs.12213

Clark DA. 2011. Changes in pastoral farming practices and pasture persistence - a review. In: Mercer CF. Ed. Pasture Persistence Symposium. Grassland Research and Practice Series 15. Dunedin, New Zealand: New Zealand Grassland Association, pp 7-14. https://doi.org/10.33584/rps.15.2011.3218

Corson DC, Waghorn GC, Ulyatt MJ, Lee J. 1999. Forage analysis and livestock feeding. Proceedings of the New Zealand Grassland Association 61: 127132. https://doi.org/10.33584/jnzg.1999.61.2340 
Devantier BP, Stevens DR, Rennie GM, Tozer KN. 2017. The effect of deferred grazing in spring and early summer pastures on pasture growth rate and feed quality. Journal of New Zealand Grasslands 79: 181-188. https://doi.org/10.33584/jnzg.2017.79.550

Dodd MB, Chapman DF, Ogle G. 2018. Regrassing trends and drivers in the New Zealand dairy industry. Journal of New Zealand Grasslands 80: 177-184. https://doi.org/10.33584/jnzg.2018.80.342

Faville MJ, Crush JR, Hong W, Phillips H, Lee JM, Chapman DF. 2020. Effect of pasture age on the genotype and phenotype of perennial ryegrass. Grass and Forage Science 75: 135-144. https://doi. org/10.1111/gfs.12474

Fulkerson WJ, Donaghy DJ. 2001. Plant-soluble carbohydrate reserves and senescence - key criteria for developing an effective grazing management system for ryegrass-based pastures: a review. Australian Journal of Experimental Agriculture 41: 261-275. https://doi.org/10.1071/EA00062

Griffiths WM, Matthew C, Lee JM, Chapman DF. 2017. Is there a tiller morphology ideotype for yield differences in perennial ryegrass (Lolium perenne L.)? Grass and Forage Science 72: 700-713. https:// doi.org/10.1111/gfs. 12268

Harris SL, Waugh CD, McCabe RJ, van Vught VT. 1999. Effect of deferred grazing during summer on white clover content of Waikato dairy pastures, New Zealand. New Zealand Journal of Agricultural Research 42: 1-7. https://doi.org/10.1080/00288233. 1999.9513347

Hernandez Garay A, Hodgson J, Matthew C. 1997a. Effect of spring grazing management on perennial ryegrass and ryegrass-white clover pastures 1 . Tissue turnover and herbage accumulation. New Zealand Journal of Agricultural Research 40: 25-35. https:// doi.org/10.1080/00288233.1997.9513227

Hernandez Garay A, Matthew C, Hodgson J. 1997b. Effect of spring grazing management on perennial ryegrass and ryegrass-white clover pastures 2 . Tiller and growing point densities and population dynamics. New Zealand Journal of Agricultural Research 40: 37-50. https://doi.org/10.1080/002882 33.1997.9513228

Hernandez Garay A, Matthew C, Hodgson J. 1999. Tiller size-density compensation in ryegrass miniature swards subject to differing defoliation heights and a proposed productivity index. Grass and Forage Science 54: 347-356. https://doi.org/10.1046/ j.1365-2494.1999.00187.x

L'Huillier PJ, Aislabie DW. 1988. Natural reseeding in perennial ryegrass/white clover dairy pastures. Proceedings of the New Zealand Grassland Association 49: 111-115. https://doi.org/10.33584/ jnzg.1988.49.1812
Lee JM, Donaghy DJ, Roche JR. 2008. Effect of defoliation severity on regrowth and nutritive value of perennial ryegrass dominant swards. Agronomy Journal 100: 308-314. https://doi.org/10.2134/ agronj2007.0099

Lee JM, Matthew C, Thom ER, Chapman DF. 2012. Perennial ryegrass breeding in New Zealand: a dairy industry perspective. Crop and Pasture Science 63: 107-127. https://doi.org/10.1071/CP11282

Lee JM, Thom ER, Waugh CD, Bell NL, McNeill MR, Wilson DJ, Chapman DF. 2017. Trajectory and causes of decline in the botanical composition of dairy-grazed pasture in the Waikato. Journal of New Zealand Grasslands 79: 83-88. https://doi. org/10.33584/jnzg.2017.79.546

Lee JM, Thom ER, Chapman DF, Wynn K, Waugh D, Rossi L, Faville MJ, Bell NL, McNeill MR. 2018. High perennial ryegrass seeding rates do not negatively impact pasture sward persistence. Grass and Forage Science 73: 456-472. https://doi.org/10.1111/gfs.12335

Macdonald KM, Glassey CB, Rawnsley RP. 2010. The emergence, development and effectiveness of decision rules for pasture based dairy systems. In: Edwards GR \& Bryant RH. Eds. Proceedings of the $4^{\text {th }}$ Australasian Dairy Science Symposium. Caxton Press, Christchurch, New Zealand, pp. 199-209.

Mansfield S, Ferguson CM, Gerard PJ, Hodges D, Kean JM, Phillips CB, Hardwick S, Zydenbos SM. 2021. Climate change impacts on pest ecology and risks to pasture resilience. In: Douglas GB. Ed. Resilient Pastures Symposium. Grassland Research and Practice Series 17. Dunedin, New Zealand: New Zealand Grassland Association, pp. 123-138. https:// doi.org/10.33584/rps.17.2021.3477

Matthew C, Xia JX, Hodgson J, Chu ACP. 1989. Effect of late spring grazing management on tiller age profiles and summer-autumn pasture growth rates in a perennial ryegrass (Lolium perenne L.) sward. Proceedings of the XVI International Grassland Congress, Nice, France, pp. 521-522.

Matthew C, Chu ACP, Hodgson J, Mackay AD. 1991. Early summer pasture control: what suits the plant? Proceedings of the New Zealand Grassland Association 53: 73-79. https://doi.org/10.33584/ jnzg.1991.53.2008

Matthew C, Lemaire G, Sackville Hamilton NR, Hernandez-Garay A. 1995. A modified self-thinning equation to describe size/density relationships for defoliated swards. Annals of Botany 76: 579-587. https://doi.org/10.1006/anbo.1995.1135

McCallum DA, Thomson NA, Judd TG. 1991. Experiences with deferred grazing at the Taranaki Agricultural Research station. Proceedings of the New Zealand Grassland Association 53: 79-83. https://doi.org/10.33584/jnzg.1991.53.1996 
Parsons AJ, Edwards GR, Newton PD, Chapman DF, Caradus JR, Rasmussen S, Rowarth JS. 2011. Past lessons and future prospects: plant breeding for yield and persistence in cool-temperate pastures. Grass and Forage Science 66: 153-172. https://doi. org/10.1111/j.1365-2494.2011.00785.x

O’Connor JR, Jahufer MZZ, Lyons T. 2020. Examining perennial ryegrass (Lolium perenne L.) persistence through comparative genetic analysis of two cultivars after nine years in the field. Euphytica 216: 36. https://doi.org/10.1007/s10681-020-2568-1

SAS Institute Inc. 2016. SAS ${ }^{\circledR}$ 9.4. SAS Institute Inc., Cary, NC, USA.
Tozer KN, Muller K, Craven T, Tarbotton I, Coster A, Burke R, Sherlock J, Cameron C. 2020. Effect of deferred grazing during late spring and summer on pasture productivity in Waikato and Bay of Plenty hill country. Journal of New Zealand Grasslands 82: 111-119. https://doi.org/10.33584/jnzg.2020.82.448

Wims CM, Lee JM, Rossi L, Chapman DF. 2014. Variation in the reproductive development of perennial ryegrass (Lolium perenne L.) cultivar. Proceedings of the New Zealand Grassland Association 76: 189-192. https://doi.org/10.33584/ jnzg.2014.76.2938 